\title{
Contributions of stimulus-incentive and stimulus-response-incentive contingencies to response acquisition and maintenance
}

\author{
JACQUES LAJOIE and DALBIR BINDRA \\ McGill University, Montréal, Québec, Canada
}

\begin{abstract}
The effects of stimulus-incentive (S:IS) contingency, stimulus-response-incentive (S:R:IS) contingency, and stimulus-no-response-incentive (S: $\bar{R}: I S)$ contingency on the acquisition and maintenance of an instrumental approach-contact response in the rat were studied. The experiment, concerned mainly with the temporal distribution of responses, showed that (1) the S:IS contingency and the S:R:IS contingency produced the same temporal distribution of responses; (2) the S:R:IS contingency produced higher rates of response than the S:IS contingency; (3) the negative $S: \bar{R}: I S$ contingency did not completely eradicate already established responses; and (4) post-CS responding occurred on reinforced trials. Consideration of these results indicates that the critical factor determining the higher rates of response under the S:R:IS contingency may be the $\mathrm{S}: \overline{\mathrm{R}}: \mathrm{IS}$ occasions experienced only in the instrumental procedure.
\end{abstract}

It is now well established that a contingency between an initially neutral stimulus and an incentive (or reinforcing) stimulus (S:IS), in the absence of any responseincentive (R:IS) contingency, can generate uniform and stable patterns of action that are manifestly like operants or instrumental responses. The evidence for the sufficiency of S:IS contingencies for producing or influencing instrumental responses comes most clearly from studies of autoshaping (e.g., Brown \& Jenkins, 1968; Gamzu \& Schwartz, 1973; Gamzu \& Williams, 1971; Locurto, Terrace, \& Gibbon, 1976; Stiers \& Silberberg, 1974; Wasserman, 1973, 1975) Williams \& Williams, 1969; Woodruff, Conner, Gamzu, \& Williams, 1977). The theoretical schemes that have been proposed to accommodate the findings of these studies range from those that attribute important roles to both S:IS and R:IS contingencies (e.g., Bolles, 1972; Estes, 1969, 1972; Hearst \& Jenkins, 1974; Schwartz \& Gamzu, 1977; Walker, 1969) to those that try to make the S:IS contingency the most important, if not the sole, basis of the observed learned modifications (e.g., Bindra, 1972, 1974, 1976; Lajoie \& Bindra, 1976; Moore, 1973). However, little progress has been made so far toward experimentally understanding the relative roles of the two contingencies in the acquisition or performance of different types of responses.

The main reason for this lack of progress is undoubt-

This article is based on portions of a dissertation by J. Lajoie for the degree of $\mathrm{PhD}$ from McGill University. The work was supported by Grant A7918 from the National Research Council of Canada and by a grant from the Quebec Ministry of Education to Dalbir Bindra. Reprints may be obtained from J. Lajoie, Département de Psychologie, Université du Québec à Montréal, Case Postale 8888, Succursale "A," Montréal, Québec, Canada H3C 3P8. edly the great difficulty of separating experimentally the influence on test response of the R:IS contingency from that of the S:IS contingency. Since the performance of any specified instrumental response must involve observation of the stimulus complex in relation to which the response is to be made, both the observation of that stimulus complex and occurrence of that response are normally inseparable and both are followed by the incentive stimulus (S:R:IS). This being so, it appears impossible to isolate, in instrumental training, the response-determining stimuli (the critical responsedetermining stimulus complex, e.g., the manipulandum) from the actual occurrence of the response (the movements that make up the response, e.g., pressing the manipulandum); at least no one has yet devised a paradigm in which the roles of these two are clearly separated. The problem has to be approached indirectly.

Woodruff, Conner, Gamzu, and Williams (1977) approached that problem in pigeons by using a twocomponent multiple schedule of reinforcement. The stimulus-incentive contingency was manipulated by varying the relative durations of the two schedule components. The response-incentive contingency was manipulated by varying the percentage of delayed IS. Both contingencies were found to interact in determining rate of keypecking.

The approach we adopted was to ask what the difference was in the details of responding between the behavior generated under an S:IS alone and the behavior generated by a combined S:IS and R:IS (or S:R:IS) contingency. The particular details of responding on which we concentrated were suggested as being possibly important by Lajoie and Bindra (1976). According to them, the acquisition and maintenance of a response in both autoshaping and instrumental training depends 
solely on the S:IS contingency. Any differences in responding observed under the S:IS and under the S:R:IS contingencies (Schwartz \& Williams, 1972; Wasserman, Hunter, Gutowski, \& Bader, 1975) they attributed to possible differences in the distribution of responses in time and space owing to the greater specificity of the conditions of reinforcement (IS presentation) in the case of the S:R:IS contingency than in the case of the S:IS contingency. In this study, we compared the details of response frequency and the temporal pattern of responding in the hope of revealing something about the roles of S:IS and R:IS contingencies in learning.

We used hooded rats and examined the acquisition and maintenance of the simple approach-contact responses. The rats were thirsty, and the reinforcement consisted of the presentation of water (IS). The lighting of a panel served as the conditioned stimulus which signaled water delivery (S:IS). The test chamber we designed for use with rats was similar to the one used with pigeons; that is, the CS upon which IS was contingent and the manipulandum used to measure the response were the same object, namely, a wire-grid panel which, when illuminated, served as the CS. We compared the influence on response acquisition and performance of an S:IS contingency alone with the combined influence of both S:IS and R:IS (or S:R:IS) contingencies, not only during the presentation of the CS but also during the interstimulus interval. Differences in both response rate and temporal distribution of responses were studied. The effect of the introduction of an omission procedure on responding under the two conditions was also examined.

\section{METHOD}

\section{Subjects}

The subjects were 10 naive male hooded rats weighing 245-255 $\mathrm{g}$ at the time of purchase from the Quebec Breeding Farm. They were individually housed.

\section{Apparatus}

The experiment was conducted in a test chamber, $30.5 \mathrm{~cm}$ long, $30.5 \mathrm{~cm}$ wide, and $19.7 \mathrm{~cm}$ high. All the walls were made of Plexiglas; the north wall was painted black, the west wall was unpainted, and the other two walls were painted brown. The floor, placed over a sawdust pan, consisted of steel bars. The ceiling was an opaque white Plexiglas sheet under a neon light. A brown filter was placed between the light and the ceiling, reducing the chamber's luminance to $46 \mathrm{~cd} / \mathrm{m}^{2}$, as measured from the floor in the center of the box. The test chamber was itself placed in a sound-protected enclosure, $122 \mathrm{~cm}$ long, $122 \mathrm{~cm}$ wide, and $61 \mathrm{~cm}$ high. A Plexiglas door on the roof of the enclosure permitted observation of the animal through a mirror placed near the transparent wall of the test chamber. $A$ ventilating fan assured proper air circulation and created a quasi-white noise of $70 \mathrm{~dB}$ (measured inside the test chamber), which masked the equipment sounds.

A "reinforcement drawer" was located in the middle of the black wall, its center $38 \mathrm{~mm}$ from the floor. As shown in Figure 1 , the front panel of the drawer consisted of a square (31.75 $\times 31.75 \mathrm{~mm}$ ) copper-wire grid placed on a white Plexiglas sup- port and bound by a black frame. The drawer was attached to a retractable lever apparatus (Lehigh Valley Electronics, No. 123-05), with the lever replaced by the drawer. When extended into the test chamber, the drawer was $22 \mathrm{~mm}$ long with black sides. A lamp ( $28 \mathrm{~V} \mathrm{dc}$ ), located inside the drawer, could illuminate the wire-grid panel, bringing the luminance of the panel to $343 \mathrm{~cd} / \mathrm{m}^{2}$, as measured at a distance of $5 \mathrm{~cm}$ from the front of the grid. In the middle of the upper surface of the drawer was a recessed circular cavity $(9.5 \mathrm{~mm}$ in diameter) which could hold $.3 \mathrm{cc}$ of water. The lighting of the panel was used as the CS, and the water, as the IS (US or reinforcer).

A drinkometer circuit (BRS, Series 100) was connected to the wire grid in front of the drawer and was used to record consummatory responses and to control, through logic modules, the delivery of water for the next trial. That is, if the rat did not drink on a given trial, the solenoid delivering water was blocked at the next trial, so that the same amount of water was available to the rat on each trial.

Automatic scheduling and recording of approach and consummatory responses (drinkometer contacts) were controlled by a set of logic modules (BRS-Foringer, Series 100) and by an online computer (PDP-8/S).

\section{Procedure}

On each of the first 3 days of the experiment, the animals were individually handled and allowed to explore the apparatus for $10 \mathrm{~min}$. They were then placed on a $221 / 4-\mathrm{h}$ water-deprivation schedule. For the next 5 days, they were exposed to the complete experimental procedure (see below) except for the presentation of the CS; water was given on each "trial" regardless of their behavior. Two subjects were discarded because they did not drink from the drawer. The remaining eight animals were then randomly distributed into two groups, a S:IS "stimuluscontingent" group ( $\mathrm{SC}$ group, $\mathrm{n}=4$ ) and a $\mathrm{S}: \mathrm{R}: \mathrm{IS}$ "responsecontingent" group (RC group, $n=4$ ).

Each daily training session lasted $30 \mathrm{~min}$ and consisted of 20 trials. In each trial, the panel was illuminated (CS) for $8 \mathrm{sec}$. At the termination of the light, the drawer was extended into the chamber for $4 \mathrm{sec}$ and then retracted into the wall. The extension and retraction time of the drawer was 2 sec each, so

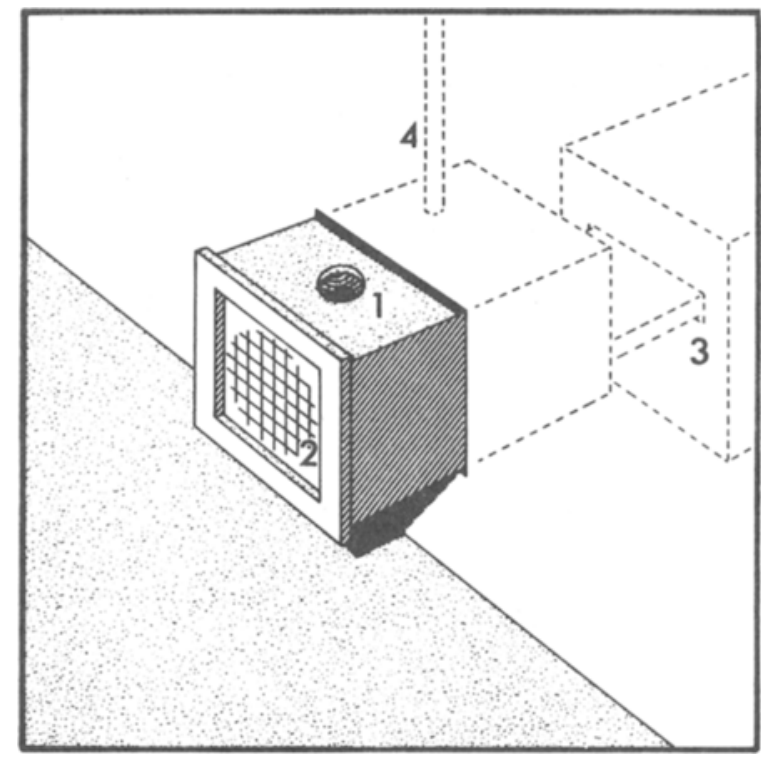

Figure 1. The "drawer" in the extended position. (1) Water receptacle (IS). (2) Wire-grid panel (CS). (3) Modified retractable lever apparatus. (4) Water tube. 
that the total drawer presentation time was $8 \mathrm{sec}$; the water receptacle was accessible during 6 of the $8 \mathrm{sec}$. The length of the intertrial interval was variable, the average being $64 \mathrm{sec}$, the shortest $48 \mathrm{sec}$, and the longest $80 \mathrm{sec}$. Intertrial intervals were randomly distributed within each session. After each session, the animal was returned to its cage and, $1 \mathrm{~h}$ after, was given water ad lib for $15 \mathrm{~min}$; it was then deprived until the next session (221/4 h later).

Three training procedures were used: (1) the stimuluscontingent training procedure (S:IS), in which IS was presented at the end of the CS period regardless of the behavior of the animal; (2) the stimulus and response-contingent training procedure ( $\mathrm{S}: \mathrm{R}: \mathrm{IS}$ ), in which the reinforcer was presented at the end of the 8-sec CS period only if at least one response (contact with the illuminated panel) had been made during the CS period; and (3) the omission-training procedure (S: $\bar{R}: I S)$, in which the reinforcer was presented at the end of the CS period only if no response (contact with the panel) had been made during the CS. The SC group was given 36 daily sessions of the stimuluscontingent training, and the RC group was given 36 sessions of the stimulus and response-contingent training ( $S: R: I S)$. Both groups were then given 24 sessions of omission training (S: $\overline{\mathrm{R}}: \mathrm{IS})$.

\section{Analysis of the Data}

In a first, rough, analysis of the temporal distribution of response, each trial was divided into four periods: (1) a $20-\mathrm{sec}$ pre-CS period, (2) an 8-sec CS period, (3) a 20-sec post-CS period, and (4) an intertrial interval (between the end of the post-CS period and the beginning of the next pre-CS period), which varied from 8 to $40 \mathrm{sec}$. The two groups were compared with respect to the average response rates (rate scores) for each period, as well as with respect to the number of trials (trial scores) on which at least one response was made during the CS period. In a second, more detailed analysis of the temporal distribution of responses, we examined the response rate for each 2 -sec interval of the pre-CS, CS, and post-CS periods, grouped in blocks of four sessions.

\section{RESULTS}

Results from the 36 sessions of stimulus-contingent training (Group SC) and stimulus-response contingent training (Group RC), as well as from the 24 sessions of omission training, are shown in Figure 2. Rate scores for the two groups are presented for: (a) the intertrial (ITI) period, (b) the 20-sec pre-CS period, (c) the 8-sec CS period, and (d) the 20-sec post-CS period. Results in terms of trial scores are shown in section e of the figure.

Inspection of Figure 2 reveals that the rate scores were generally greater for Group RC than for Group SC during the intertrial period, the pre-CS period, and the CS period, but not during the post-CS period; the differences between the groups increased steadily from the intertrial period to the CS period. Rate scores showed a general increasing trend during the CS period over the 36 training sessions in the $\mathrm{RC}$ group and over the 15 first training sessions in the $\mathrm{SC}$ group, but during the pre-CS period only in the $\mathrm{RC}$ group. During the postCS period, the rate scores decreased, in both groups, from the maximum attained on about the 10th session.

Separate analyses of variance were carried out on rate scores for each period and on trial scores for the CS period. Owing to the small number of subjects, conserva- tive degrees of freedom for designs having repeated measures were used (see Winer, 1962, p. 322). The same design was used in each of the five analyses, that is, a three-way analysis of variance (Blocks by Sessions by Groups) with repeated measures on the first two factors. There were two groups and 60 sessions, nested in five blocks of 12 sessions. The first three blocks of sessions included all 36 acquisition training sessions and the last two blocks of sessions included all the omission training sessions.

No significant differences between groups of blocks were found for the ITI period analysis, the pre-CS period analysis, and the post-CS period analysis; however, for the CS period analysis, a significant difference between blocks $[\mathrm{F}(4,24)=7.7, \mathrm{p}<.01]$ and a significant interaction between blocks and groups $[F(4,24)=$ $3.4, \mathrm{p}<.05]$ were found. This difference between

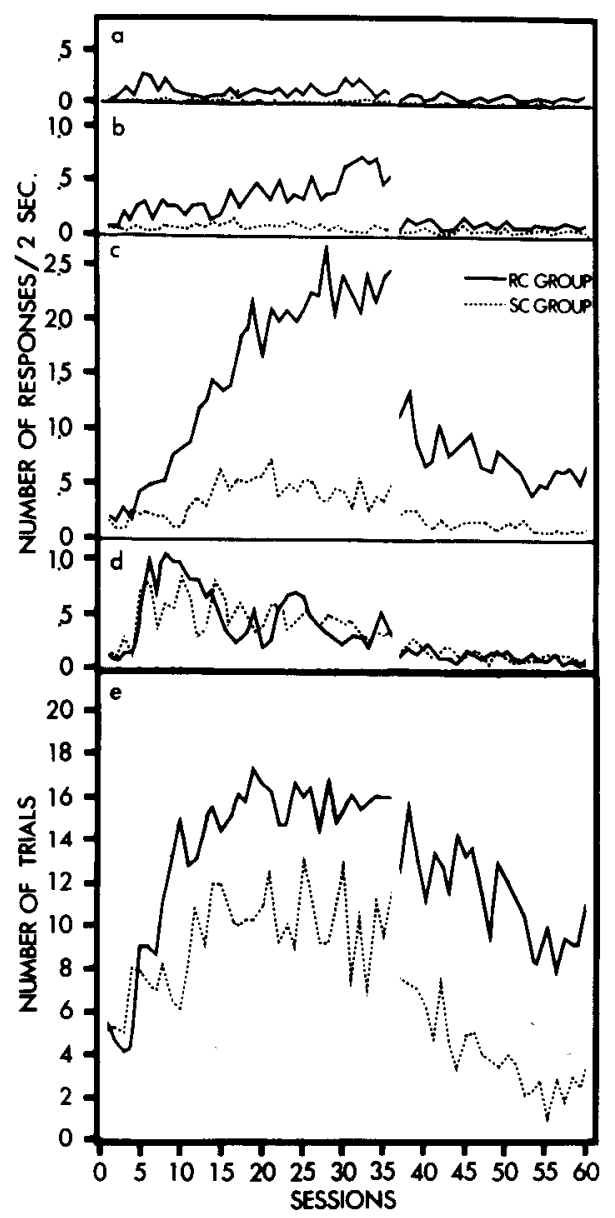

Figure 2. Results from the 36 sessions of stimulus-contingent training (SC group) and response-contingent training (RC group) and for 24 sessions of omission procedure (both groups). Average response rates (total number of responses divided by the number of 2 -sec intervals) for (a) the intertrial period, (b) the 20-sec pre-CS period, (c) the 8-sec CS period, and (d) the 20-sec post-CS period; (e) number of trials during which at least one response was made for the 36 training sessions and 24 omission-procedure sessions. 
blocks was further examined with the Newman-Keuls test, and two pairwise comparisons were found significant (Block 3-Block 1, p <.05; Block 2-Block 1, $p<.05$ ). Also, a separate Newman-Keuls analysis performed on the RC group revealed a significant difference between Block 2 and Block $1(p<.05)$ and between Block 3 and Block $1(\mathrm{p}<.05)$. However, no differences between blocks were found for the SC group with the Newman-Keuls procedure. Test of simple effects performed for each block revealed a significant difference between the two groups at Block $2[t(6)=$ $2.5, \mathrm{p}<.05]$ and Block $3[\mathrm{t}(6)=3.8, \mathrm{p}<.01]$.

While the two groups were significantly different in the average asymptotic response rates during the CS period, there was no significant difference between the groups in trial scores. However, there was a significant difference between blocks $[F(4,24)=11, p<.01]$, and this difference was confirmed as significant by the Newman-Keuls procedure: as with the rate scores, a significant difference was found between Block 2 and Block $1(p<.05)$ and between Block 3 and Block 1 $(p<.05)$. Thus, rate scores and trial scores during the training period were quite different. A significant increase over sessions was found only in the RC group for rate scores but in both $\mathrm{SC}$ and $\mathrm{RC}$ groups. for trial scores. Also, a significant difference between SC and RC groups during training sessions was found in rate scores but not in trial scores.

The introduction of the omission procedure (the last 24 sessions) produced an immediate decrease in rate scores during the CS period in both groups, but the decrease was greater in the RC group. During the other periods, response rates also diminished at the first session of omission training but then remained at the same level until the last session. The number of trials on which at least one response was made during the CS period did not show any substantial decrease at the onset of the omission procedure, but declined gradually over several sessions; however, the trial scores were still considerably above zero in both groups at the end of omission training.

Analysis of the rate scores with the Newman-Keuls procedure indicated a significant effect of omission training during the CS period for Group RC: Blocks 2 and 3 were significantly different from Blocks 4 and $5(p<.05)$. No difference was found in the SC group. Also, $t$ tests revealed no significant difference between groups for the two omission training blocks. Analysis of the number of trial scores with the Newman-Keuls procedure showed that, in Group RC, there was no significant difference between omission blocks (Blocks 4 and 5) and training blocks (Blocks 1,2, and 3), while in Group SC, Block 5 was significantly different from Blocks 2 and $3(p<.05)$. As with rate scores, $t$ tests revealed no significant difference between groups during the two omission training blocks. Thus, rate scores and trial scores were also different during the omission procedure. A significant reduction of rate scores was found in Group RC but not in Group SC, while a significant reduction of trial scores was found in Group SC but not in Group RC. In short, the Group RC rate scores showed a significant increase during training and a significant decrease during the omission procedure, while in Group SC these changes were not significant. In the SC group, the small decrease in rate scores may be due to a floor effect, since the $\mathrm{SC}$ rate scores at the end of acquisition sessions were already low. During training, trial scores showed a significant increase in both Group RC and Group SC, while during the omission procedure, there was a significant decrease in trial scores only in the SC group.

Rate and trial scores of each subject in both groups were plotted separately to determine whether individual scores resembled the group pattern. In general, the group scores adequately represented the individual scores. A separate statement on the data of individual animals may be obtained by writing to the second author.

The goal of a more detailed temporal distribution analysis was to see if the scores obtained for each period adequately represented the distribution of responses within the period. Figures 3 and 4 are three-dimensional representations of the temporal distribution of the scores within the trial. The scores are presented on the $\mathrm{z}$ scale. On the $\mathrm{x}$ scale are presented, from left to right, in blocks of 2-sec intervals, the pre-CS period (10 units), the CS period (4 units), the water-presentation period (4 units), and the post-CS period (10 units). The sessions are presented on the $y$ scale, from front to rear, grouped in blocks of four sessions. The first 9 units represent the 36 training sessions and the last 6 units represent the 24 sessions of omission training. Figure 3 shows the SC group scores and Figure 4 shows the RC group scores.

The results of this detailed "temporal-distribution" analysis generally confirmed the results of the earlier, rough "period" analysis, Group RC scores were greater than Group SC scores at all moments (2-sec intervals) of the pre-CS and CS periods. During the post-CS period, scores were quite similar in both groups, except during omission sessions. During the pre-CS period, there was no detectable increase in scores in any of the two groups, but there was a regular increase of the RC group scores among blocks of training sessions at each of the 102 -sec blocks. During the CS period, a goalgradient pattern of responses appeared in both groups and persisted through the end of the experiment. During the post-CS period, the RC group scores increased rapidly to a maximum and then decreased regularly throughout the rest of the post-CS period. However, the decrease in the scores tended to be increasingly rapid over sessions. Group SC scores followed the same pattern except that the scores were already at their maximum at the beginning of the post-CS period. In both groups, at the end of the post-CS period, the scores were at the same level at the beginning of the pre-CS period.

The omission procedure affected the RC group post- 


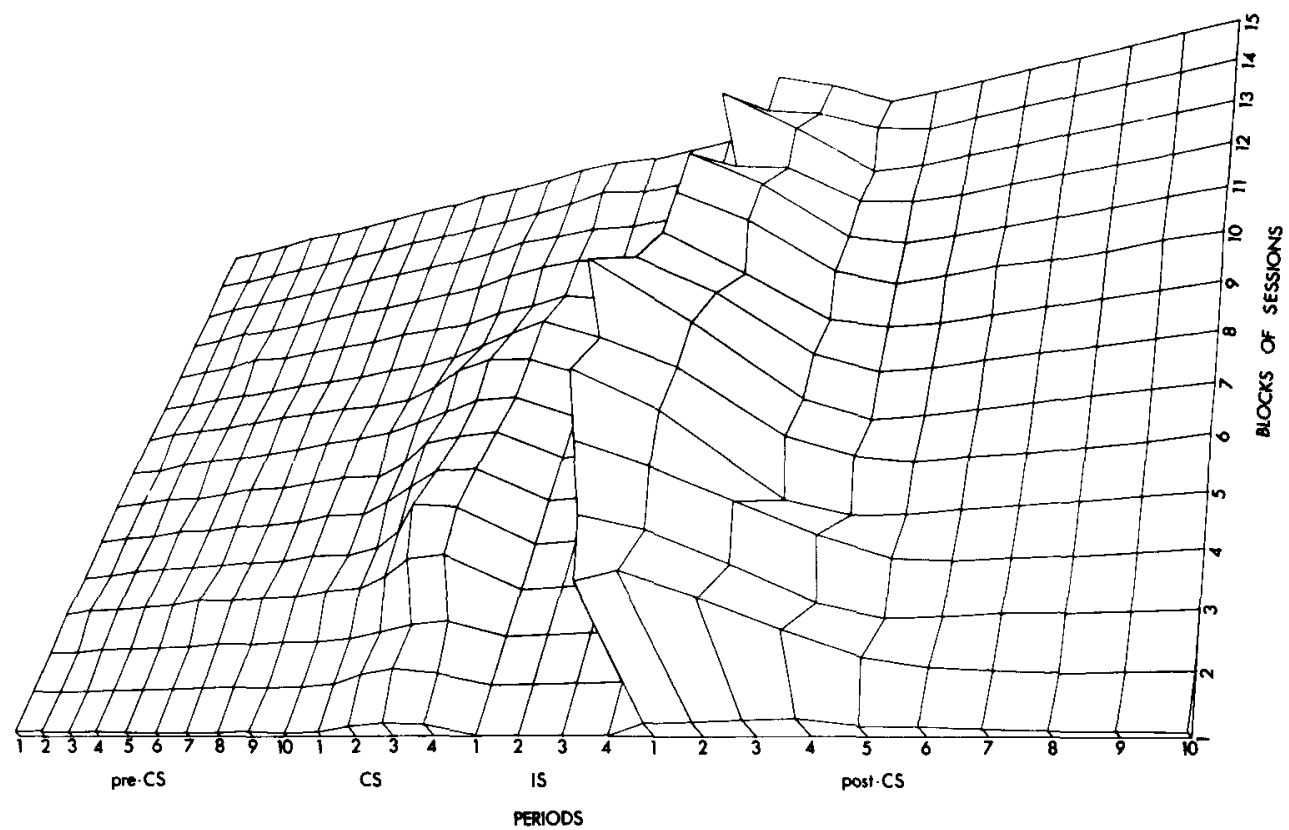

Figure 3. Three-dimensional representation of the temporal distribution of the SC group mean scores within trial for all sessions. The scores are presented on the $z$ scale. The highest score was 2.075. From left to right ( $x$ scale) are presented, in blocks of 2-sec moments, the pre-CS period (10 blocks), the CS period (4 blocks), the water presentation period ( 4 blocks), and the post-CS period (10 blocks). From front to rear ( $y$ scale) are presented all 60 sessions, grouped in blocks of four sessions. The first nine blocks represent the 36 training sessions and the last six blocks represent the 24 sessions of omission training.

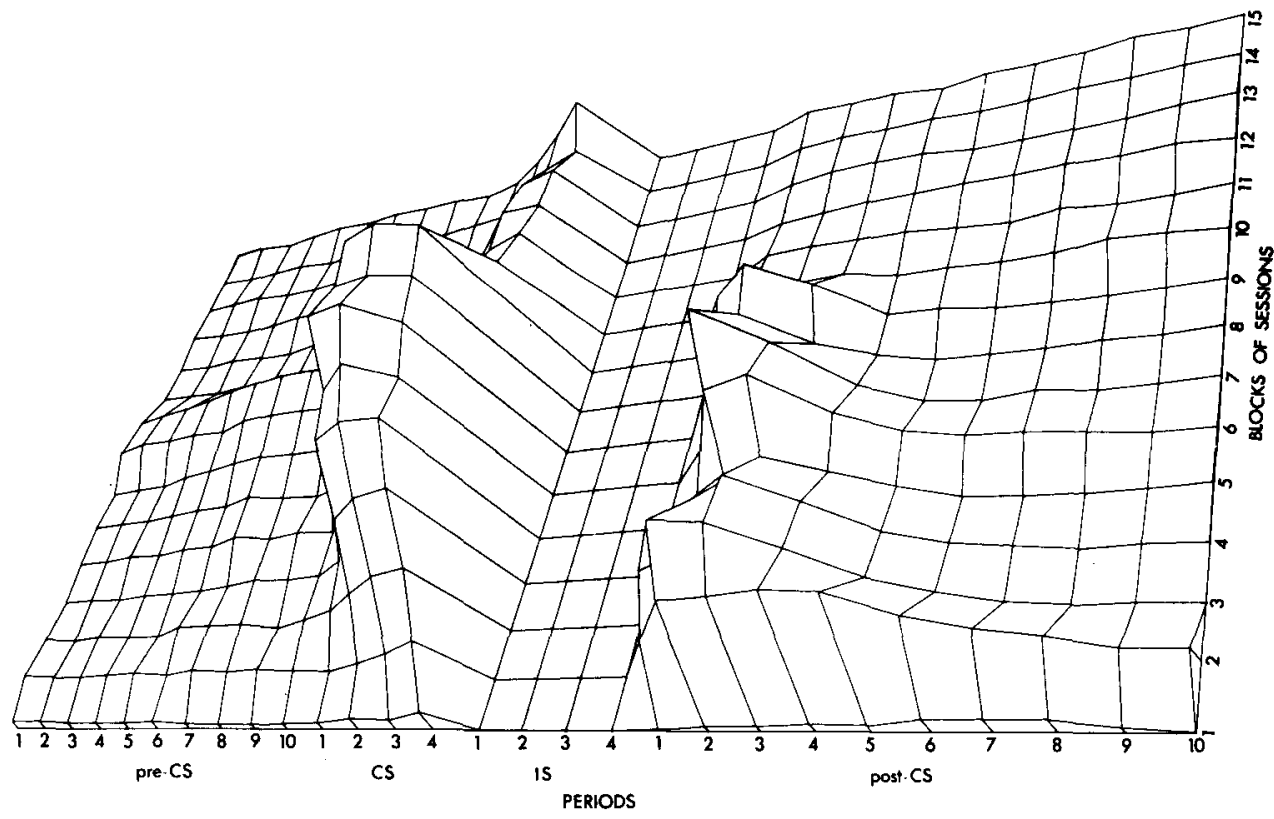

Figure 4. Three-dimensional representation of the temporal partition of the RC group mean scores within trial for all sessions. The highest score was 2.81. (See Figure 3 for more explanation.) 
CS scores more than it did the post-CS scores of Group SC. It must be noted, however, that responding during the post-CS period occurred only on trials when IS was presented. Thus, high rates of response during the CS period in Group RC must have prevented IS from appearing, resulting in low post-CS rates, while the relatively low rate of responding during the CS period in Group SC allowed more presentations of IS, resulting in less decline in post-CS rates (see Figure 2e). All scores, from the beginning of the pre-CS period to the end of the CS period, decreased considerably within the first four sessions of omission procedure (Block 10 of sessions). Most of that decrease occurred immediately, on the very first session of omission training, as it has already been shown (see Figure 2). However, after that immediate decrease, the scores decreased little during the following sessions.

\section{DISCUSSION}

The results of the SC group confirm that stable operant responding with response-independent CS-contingent reinforcement can be achieved in the rat if the CS and the manipulandum are the same stimulus object (Locurto, Terrace, \& Gibbon, 1976; Stiers \& Silberberg, 1974). The S:IS contingency thus appears to have been sufficient to instigate what appears in all respects to be an instrumental approach-contact response. Even if there existed a de facto instrumental (R:IS) contingency after responding had begun, the S:IS contingency must still be considered sufficient for instigating the initial responses made before the $R$ :IS contingency could have acquired any great strength.

A comparison of the RC group with the SC group during the 36 acquisition training sessions indicates that the superimposition of the explicit R:IS contingency produced a substantially higher rate of response in the RC group (Schwartz \& Williams, 1972; Wasserman, Hunter, Gutowski, \& Bader, 1975). However, the two groups did not differ significantly in the probability of making at least one response during the CS period. This suggests that probability of making an approachcontact response in relation to the CS-manipulandum is determined primarily by the S:IS contingency; what the $\mathrm{R}$ :IS contingency adds is an increase in the rate of responding. This suggestion is supported by the results of the omission-training session.

The omission procedure (S: $\bar{R}: I S)$ reduced the rate of responding, especially in the $\mathrm{RC}$ group, but failed to produce total extinction of the response, as might be expected to occur in the absence of the R:IS contingency. In the SC group, the small decrease in rate scores is probably due to a floor effect, as mentioned before. The effect of omission training on number-oftrial scores is more surprising. Even though the introduction of the omission procedure might be expected to constitute a greater alteration in Group RC (from $S: R: I S$ to $: \bar{R}: I S$ ) compared to Group SC (from S:IS to $S: \bar{R}: I S$ ), the performance in the RC group was nonetheless less affected than performance in the SC group; this was shown by the absence in Group RC of any significant decrease in number-of-trial scores during omission training, while performance in the SC group was significantly lower at the end of omission training than at the end of acquisition training. In other words, resistance to omission training was greater in Group RC than in Group SC as judged by trial scores, while it was lower as judged by rate scores. It would appear that there were two components to the observed response rates, one determined by the S:IS contingency that was common to the two groups, and the other determined by the R:IS contingency, which was stronger in the RC group than in the SC group; the disappearance of the R:IS contingency during omission training immediately reduced response rates. But higher resistance to omission in probability of responding (trial scores) revealed that the $\mathrm{S}$ :IS contingency had a stronger influence in Group RC than in Group SC.

The post-CS responses occurred at a time when the interval to the next IS presentation was the longest, and at the time when the panel was not illuminated; thus they surely cannot be interpreted as anticipatory responding. Since this post-CS responding occurred only on "reinforced" trials, it could represent a continuation of the unconditioned response (licking) after the removal of IS. Such a continuation of unconditioned responses has been reported by Shapiro (1960) in the salivary response of dogs, accompanying leverpressing under a FI $2 \mathrm{~min}$. The rate of salivary responding was at its highest immediately after the presentation of IS (a food pellet), then declined, and this period of low responding was followed by a gradual increase as the next reinforcement approached. But even if there is a parallel between the post-CS salivary response reported by Shapiro and the panel approach-contact responses of the present experiment, it would not explain why the animals in our experiment responded on the panel. It is more likely that the post-CS responding in our experiment is related to such phenomena as adjunctive behavior (Falk, 1971), emotional induction (Segal, 1972), or interim activities (Staddon \& Simmelhag, 1971), that generally appear during the interincentive interval.

We turn now to the fundamental question: What is it about the instrumental procedure (S:R:IS) that produces the higher rate of response than the autoshaping or classical (S:IS) procedure? The S:IS procedure and the S:R:IS procedure used in this experiment were quite similar. In both procedures, IS was contingent upon CS. Also, in both procedures, the absence of IS was contingent upon the absence of illumination of the panel. It has already been found that, to be effective, the S:IS (light:food) occasions (experience) must be contrasted with either a "no-light no-food" occasion 
(Gamzu \& Williams, 1971) or a "no-light less-food" occasion (Gamzu \& Schwartz, 1973). If the probability of getting food is the same when the light is off as when the light is on, the CS response will not develop or, if already developed, will be extinguished. The main difference between the two procedures would appear to be in the requirement of a contact response during the CS period: IS was always presented in the classical procedure (SC group), but was presented in the instrumental procedure only if a response occurred during the CS period. In other words, $S: \bar{R}: \overline{I S}$ occasions were experienced only in the instrumental procedure. Thus the $S: \bar{R}: \overline{I S}$ occasions appear to be critical in determining the higher rates of response met in the RC group, even if they are not essential in the acquisiton and maintenance of the response. But the exact process by which these $S: \bar{R}: \overline{I S}$ occasions have their effect is not clear from the results of this experiment.

\section{REFERENCES}

BindRA, D. A unified account of classical conditioning and operant training. In A. H. Black \& W. F. Prokasy (Eds.), Classical conditioning II: Current theory and research. New York: Appleton-Century-Crofts, 1972.

BindRA, D. A motivational view of learning, performance, and behavior modification. Psychological Review, 1974, 81, 199-213.

BindRA, D. A theory of intelligent behavior. New York: Wiley, 1976.

Bolles, R. C. Reinforcement, expectancy, and learning. Psychological Review, 1972, 72, 394-409.

Brown. P. L., \& Jenkins, H. M. Auto-shaping of the pigeon's keypeck. Journal of the Experimental Analysis of Behavior, $1968,11.1-8$.

Estes, W. K. New Perspectives on some old issues in association theory. In N. J. Mackintosh \& W. K. Honig (Eds.), Fundamental issues in associative learning. Halifax. Nova Scotia: Dalhousie University Press, 1969.

Estes, W. K. Reinforcement in human behavior. American Scientist, 1972, 60, 723-729.

FALK, J. L. The nature and determinants of adjunctive behavior. Physiology and Behavior, 1971, 6, 577-588.

Gamzu, E., \& Schwartz, B. The maintenance of key pecking by stimulus contingent and response-independent food presentation. Journal of the Experimental Analysis of Behavior, 1973, 19. 65-72.

Gamzu, E. \& Williams, D. R. Classical conditioning of a complex skeletal response. Science, 1971, 171, 923-925.

Hearst, E., \& Jenkins, H. M. Signtracking: The stimulusreinforcer relation and directed action. Austin, Texas: Psychonomic Society, 1974.
LAJOIE, J., \& BINDRA, D. An interpretation of autoshaping and related phenomena in terms of stimulus-incentive contingencies alone. Canadian Journal of Psychology, 1976, 30, 157-173.

Locurto, C., Terrace, H. S., \& Gibion, J. Autoshaping, random control. and omission training in the rat. Journal of the Experimental Analysis of Behavior, 1976, 26, 451-462.

Moore, B. R. The role of directed Pavlovian reactions in simple instrumental learning in the pigeon. In R. A. Hinde \& J. Stevension-Hinde (Eds.), Constraints on Learning. New York: Academic Press, 1973.

Schwartz, B., \& Gamzu, E. Pavlovian control of operant behavior: An analysis of autoshaping and its implications for operant conditioning. In W. K. Honig \& J. E. R. Staddon (Eds.), Handbook of operant behavior. New York: Prentice-Hall, 1977. Pp. 53-97.

Schwartz, B., \& Williams, D. R. The role of the response reinforcer contingency in negative automaintenance. Journal of the Experimental Analysis of Behavior, 1972, 17, 351-357.

SEGAL, E. F. Induction and the provenance of operants. In R. M. Gilbert \& J. R. Millenson (Eds.), Reinforcement: Behavioral analyses. New York: Academic Press, 1972.

SHAPIRO. M. M. Respondent salivary conditioning during operant lever pressing in dogs. Science, 1960, 132, 619-620.

Staddon, J. E. R., \& Simmelhag, V. L. The "superstition" experiment: A reexamination of its implications for the principles of adaptive behavior. Psychological Review, 1971, 78, 13-43.

Stiers, M., \& Silberberg, A. Lever-contact responses in rats: Automaintenance with and without a negative responsereinforcer dependency. Journal of the Experimental Analysis of Behavior, 1974, 22, 497-506.

W ALKER, E. L. Reinforcement-"the one ring." In J. T. Tapp (Ed.), Reinforcement and behavior. New York: Academic Press, 1969.

Wasserman, E. A. Pavlovian conditioning with heat reinforcement produces stimulus-directed pecking in chicks. Science, 1973, 181, 875-877.

Wasserman, E. A., Hunter, N. B., Gutowsxi, K. A., \& Bader, S.A. Autoshaping chicks with heat reinforcement: The role of stimulus-reinforcer and response-reinforcer relations. Journal of Experimental Psychology: Animal Behavior Processes, $1975,104,158-169$.

Williams, D. R., \& Williams, H. Auto-maintenance in the pigeon: Sustained pecking despite contingent non-reinforcement. Journal of the Experimental Analysis of Behavior, 1969, 12. $511-520$.

WINER, B. J. Statistical principles in experimental design. New York: McGraw-Hill, 1962.

Woodruff, G., Conner, N., Gamzu, E., \& Williams, D. R. Associative interaction: Joint control of key pecking by stimulus-reinforcer and response-reinforcer relationships. Journal of the Experimental Analysis of Behavior, 1977, 28, 133-144.

(Received for publication August 6, 1977; revision accepted January 5,1978 .) 